\title{
LA DESINTERMEDIACIÓN EN EL CONTRATO DE SEGURO. DE LA BANCASEGUROS AL USO DE RED*
}

\section{DISINTERMIDIATION IN THE INSURANCE CONTRACT. FROM BANK INSURANCE MODEL (BIM) TO THE USAGE OF SALES CHANNEL}

SEBASTIAN MEJIA ARAMBURO ${ }^{* *}$

Fecha de recepción: 29 de marzo de 2017 Fecha de Aceptación: 25 de abril de 2017

Disponible en línea: 30 de junio de 2017

\section{Para Citar este articulo/To cite this article}

\begin{abstract}
Mejía Aramburo, Sebastián, La desintermediación en el contrato de seguro. De la bancaseguros al uso de red, 46 Rev.Ibero-Latinoam. Seguros, 109-148 (2017). https://doi.org/10.11144/Javeriana.ris46.dcsb doi:10.11144/Javeriana.ris46.dcsb
\end{abstract}

* El presente artículo de investigación desarrolla la evolución de la bancaseguros en Colombia, hasta convertirse en uso de red, lo que muestra una ampliación en los canales y formas de comercialización, generando inclusión y penetración del sector asegurador, permitiendo el nacimiento de otras figuras como los corresponsales aseguradores.

** Director de Regulación de Suramericana. Abogado de la Universidad de Medellín. Especialista en Responsabilidad Civil y Seguros de la Universidad EAFIT. Especialista en Derecho de los Seguros de la Pontificia Universidad Javeriana. Master en Derecho Internacional de la Empresa de la Universidad de Barcelona. Correo de contacto: smejia@sura.com.co 


\section{RESUMEN}

En este trabajo nos proponemos desarrollar los antecedentes normativos para llegar a lo que hoy en día se tiene, y hacer recomendaciones acerca de lo que hace falta para propiciar canales más flexibles, e incluyentes, que generen soluciones efectivas a las necesidades de todos los sectores de la economía, y de todos los estratos socio económicos, en la totalidad del territorio nacional.

Hoy en día, la omnicanalidad del sector asegurador es una realidad creciente, lo cual ha desencadenado en el fortalecimiento del canal directo, y de las alianzas estratégicas para la comercialización de seguros, lo que a su vez ha desencadenado ampliar la penetración del sector asegurador, y una mayor inclusión financiera; esto ha generado, que el otorgamiento de productos y servicios sean cada vez más acordes a las necesidades de los asegurados.

De acuerdo con este panorama regulatorio internacional, hay una tendencia desintermediadora en la comercialización de seguros, en búsqueda de una mayor inclusión del sector aseguradora, y a su vez este pueda generar una mayor penetración en el PIB de los países, el cual es bastante bajo en nuestros países latinoamericanos.

Dentro del panorama colombiano encontramos avances regulatorios que permiten la democratización del contrato de seguro, en donde cada vez una mayor cantidad de personas, de todos los estratos socioeconómicos han tenido mayores posibilidades de adquirir un seguro, no solo por sus costos, sino también por la posibilidad de adquirirlo en una gama de lugares cada vez más amplia. No obstante consideramos que falta, sin desconocer los pasos que en la materia se han hecho, así como la buena labor que ha sido desarrollada por parte del Gobierno Nacional y de los reguladores.

Palabras clave: Bancaseguros; canales de comercialización; corresponsales de seguros; desintermediación; inclusión financiera; seguros de desgravamen; uso de red. 


\begin{abstract}
In this article our purpose is to look at the development of the normative background until we reach what we have today in regulation, then recommend what the system lacks so that the channels can become more flexible and inclusive. We aim to have channels that generate effective solutions for all the economic sectors and socio-economic strati, in all the national territory.
\end{abstract}

Today, in the insurance sector omnychanell is an increasing reality, which has led to the strengthening of the direct channel, and the strategic alliances for the commercialization of insurance. This has also broadened the penetration of the insurance sector, generating more financial inclusion, which leads to products and services that are better adjusted to the needs of the insured.

According to the international regulatory scene, there is a tendency for disintermediation in the commercialization of insurance, this looks for a bigger inclusion of the insurance sector, and a greater penetration in the GDP, which in Latin American countries is quite low.

In the Colombian panorama we can find regulatory development that allows the democratization of the insurance contract, where every time more people of all socio-economic strati have had the possibility of acquiring an insurance, not only for its cost, but also for an increasing range of places where they can acquire it. Nevertheless, we consider that there are still gaps to be filled, without ignoring all the advances that have been made, and the good doing developed by the government and the regulators.

Keywords: Bank Insurance Model(BIM) or Bancaasurance; Commercialization Channels; Debtors Insurance; Disintermediation; Financial Inclusion; Usage of Sales Channel; Insurance Correspondents.

\title{
SUMARIO
}

INTRODUCCIÓN. CAPÍTULO 1: PANORAMA INTERNACIONAL. 1.1. México.1.2. Panamá. 1.3. Perú. 1.4. El Salvador. 1.5. Guatemala.1.6. Argentina. 1.7. España. 1.8 Conclusión. CAPÍTULO 2: PANORAMA COLOMBIANO. 2.1. Normas que regulan la actividad de intermediación en seguros en Colombia. 2.1.1. Desarrollo Normativo del Uso de Red. 2.1.1.1. Uso de Red. 2.1.1.2. Características. 2.1.1.3. Ramos. 2.1.1.4. Otras formas de comercialización. 2.1.1.5. Algunas Cifras. 2.1.1.6. Seguros de Desgravamen. 2.1.1.6.1 Decreto 384 de 1993. 2.1.1.6.2. Decreto 673 de 2014. 2.1.1.6.2.1. Licitación de Seguros Diferentes a los Asociados a Créditos con Garantía Hipotecaria o Leasing Habitacional. 2.1.1.6.2.2. Licitación de Seguros Asociados a Créditos con Garantía Hipotecaria o Leasing Habitacional. 2.1.1.6.3. Decreto 1534 de 2016. 2.1.2. Apertura a la Inclusión Financiera. 2.1.3. Normatividad. 2.2. Corresponsales aseguradores. 2.3. Venta directa. 3. Beneficios y Retos de los nuevos canales. 3.1. Para los prestadores de la red. 3.2. Para las aseguradoras. 3.3. Para los intermediarios. 3.4. Para el cliente. Conclusiones 


\section{INTRODUCCIÓN}

Hasta hace unos pocos años, en el sector asegurador, se veía una fuerte diferencia en la cantidad de productos de seguros colocados por intermediarios, de cara a otros canales de comercialización.

Hoy en día la omnicanalidad, es decir la multiplicidad de formas mediante las cuales el sector asegurador llega hoy a sus consumidores, es una realidad creciente, lo cual ha desencadenado en el fortalecimiento del canal directo, y de las alianzas estratégicas para la comercialización de seguros, lo que a su vez ha permitido ampliar la penetración del sector asegurador, y una mayor inclusión financiera; esto ha generado, que el otorgamiento de productos y servicios sean cada vez más acordes a las necesidades de los asegurados.

En este trabajo nos proponemos desarrollar someramente los antecedentes normativos latinoamericanos, para luego adentrarnos en el contexto colombiano, es decir, como se ha desarrollado en Colombia el término de Bancaseguros, hasta llegar a lo que hoy conocemos como Uso de Red, sus retos y oportunidades, ello con el fin para propiciar canales más flexibles, e incluyentes, que generen soluciones efectivas a las necesidades de todos los sectores de la economía, y de todos los estratos socio económicos, en la totalidad del territorio nacional.

Asimismo precisamos que este trabajo no pretende demeritar, ni mucho menos la labor de los corredores, agentes y agencias, toda vez que es necesario destacar la labor y su papel preponderante en el desarrollo de la industria. Por el contrario, el propósito es mostrar las oportunidades que presenta la omnicanalidad, las posibilidades de negocio que ésta genera, así como resaltar la labor social de aseguramiento a los sectores más desprotegidos, o más alejados de las ciudades capitales, sin que ello necesariamente constituya una competencia entre canales.

\section{CAPÍTULO 1}

\section{PANORAMA INTERNACIONAL}

En las distintas legislaciones vemos una tendencia importante a la omnicanalidad, en algunos casos, tanto personas naturales, como jurídicas, tienen como actividad laboral una distinta a la comercialización de 
seguros, a través de la cual pueden mediante un contrato remunerado, distribuir este tipo de productos.

Los productos comercializados por medio de canales masivos, por regla general, cumplen con las siguientes características:

- Condiciones uniformes.

- De fácil comercialización.

- Responsabilidad por parte de la aseguradora ante los hechos del comercializador.

- Capacitación a los comercializadores.

- Contratos regulados de prestación de servicios o de comercialización.

Para el efecto, se abordarán algunos casos en derecho comparado, como son Argentina, El Salvador, Guatemala, México, Panamá, Perú:

\subsection{México}

El artículo 23 de la Ley General de Instituciones y Sociedades Mutualistas de Seguros ${ }^{1}$, establece que los contratos de seguro que no cumplan con

1 Artículo 23.- Para los efectos de esta Ley, se considerarán agentes de seguros las personas físicas o morales que intervengan en la contratación de seguros mediante el intercambio de propuestas y aceptaciones, y en el asesoramiento para celebrarlos, para conservarlos o modificarlos, según la mejor conveniencia de los contratantes. La intermediación de contratos de seguro que no tengan el carácter de contratos de adhesión, está reservada exclusivamente a los agentes de seguros; la intermediación de los que tengan ese carácter también podrá realizarse a través de las personas morales previstas en el último párrafo del artículo 41 de esta Ley. Para el ejercicio de la actividad de agente de seguros, se requerirá autorización de la Comisión Nacional de Seguros y Fianzas. La propia Comisión, previa audiencia de la parte interesada, podrá suspender dicha autorización hasta por dos años o revocarla, además de aplicar amonestaciones y multas a dichos agentes, en los términos de esta Ley y del reglamento respectivo. Las autorizaciones serán para una o varias operaciones o ramos; sin embargo, tratándose de la intermediación en seguros de pensiones derivados de las leyes de seguridad social, las autorizaciones sólo se otorgarán para intermediar estos seguros respecto de una sola institución de seguros, además de que se podrán otorgar autorizaciones para el ejercicio de su actividad en otras operaciones o ramos, con diversas instituciones. Las autorizaciones tendrán el carácter de intransferibles y podrán otorgarse a las siguientes personas cuando satisfagan los requisitos que se establezcan en el reglamento respectivo: a).Personas físicas vinculadas a las instituciones de seguros por una relación de trabajo, para desarrollar esta actividad; b).- Personas físicas que se dediquen a esta actividad con base en contratos mercantiles; y c).- Personas morales que se constituyan para operar en esta actividad. Las actividades que realicen los agentes de seguros se sujetarán a las disposiciones de esta Ley y del Reglamento respectivo, a las orientaciones de política general que en materia aseguradora y para el debido cumplimiento de lo previsto en el artículo 24 siguiente, señale la Secretaría de Hacienda y Crédito Público mediante 
las características de un contrato de adhesión, tienen que ser celebrados a través de agentes; sin embargo, todos aquellos que sí cumplan con esta característica, pueden ser comercializados por conducto de sociedades, a través contratos de prestación de servicios, los cuales serán previamente aprobados por la Comisión Nacional de Seguros y Finanzas.

A su turno, el artículo 41 de esta misma disposición establece que los intermediarios financieros y cualquier sociedad puede realizar contratos de prestación de servicios con empresas aseguradoras, pero deberá capacitar a los empleados y representantes de la sociedad que realicen actividades de promoción o venta de seguros.

Asimismo las aseguradoras son responsables por los daños y perjuicios que se lleguen a ocasionar a los asegurados, contratantes o beneficiarios, con la actuación de estas sociedades.

\subsection{Panamá}

En este país, se encuentra permitida la comercialización de seguros por medio de canales alternativos, de conformidad con los artículos 50 a 55 de la ley 12 de 2012, utilizando para el efecto, las redes de empresas para el contacto de clientes, y para la comercialización de productos, previa la celebración de contratos de comercialización con las aseguradoras.

Mediante este esquema, el personal que promociona y gestiona la contratación de seguros, hace parte de la entidad bancaria o comercial con quien se tiene el contrato de comercialización celebrado, previa capacitación que se haga por parte del asegurador.

Los pagos a esta entidad, bancaria o comercial, se entienden hechos a la aseguradora, y esta debe responder por los errores o perjuicios que se causen a los asegurados, o por errores en la contratación del seguro.

reglas de carácter general, así como a la inspección y vigilancia de la Comisión Nacional de Seguros y Fianzas. Les serán, además, aplicable lo dispuesto por el artículo 71 de esta Ley. Los agentes de seguros deberán reunir los requisitos que exija el Reglamento respectivo, pero en ningún caso podrá autorizarse a personas que por su posición o por cualquier circunstancia puedan ejercer coacción para contratar seguros. Los agentes de las instituciones de seguros darán aviso a la Comisión Nacional de Seguros y Fianzas, por lo menos con diez días de anticipación, del establecimiento, cambio de ubicación y clausura de sus oficinas. De igual manera se dará el aviso a los asegurados. 
Los productos deben ser de fácil comprensión, individuales, estandarizados y enfocados a venta masiva, en donde de acuerdo con la misma ley, se facilite la adquisición por parte contratantes de bajos ingresos.

\subsection{Perú}

La comercialización masiva de seguros está regulada mediante la Resolución S.B.S. N²996 de 2010.

Esta le ley permite a las empresas aseguradoras contratar con comercializadores de bienes o servicios, sean personas naturales o jurídicas, mediante contratos de comercialización, a fin de realizar la promoción y suscripción de contratos de seguros.

Al igual que en otros países, el pago al comercializador, se entiende hecho al asegurador, y éste debe responder ante el asegurado por la mala suscripción, o por los perjuicios que se le causen a tomadores o asegurados por error u omisión, impericia o negligencia.

Antes de que un comercializador pueda empezar a vender y promover contratos de seguro, es necesario que la Superintendencia de Seguros de este país, haya aprobado el contrato de comercialización celebrado con la aseguradora.

Los productos deben ser masivos, y estar desarrollados en lenguaje sencillo, así como que los mismos sean de fácil comprensión y manejo. Además, que no se requieran condiciones especiales para la suscripción, bastando únicamente el consentimiento del asegurado para el perfeccionamiento del mismo.

\subsection{E1 Salvador}

La comercialización masiva de seguros está permitida de acuerdo con el artículo 51 de Ley de Sociedades de Seguros, en ella se establece lo siguiente:

“(...). Las actividades de promoción y colocación de seguros efectuadas por las sociedades de seguros, podrán ser realizadas por medio 
de cualquier empresa o sociedad inscritas en el registro que llevará la Superintendencia, previa celebración de los convenios a que haya lugar, siempre que la contratación por parte del cliente sea voluntaria y que se trate de pólizas que sean idóneas para su comercialización masiva (...).".

Al igual que en los demás países donde se encuentra regulada la comercialización masiva de seguros, la responsabilidad la asume el asegurador.

En la NPS4-10 de la Superintendencia del Sistema Financiero se regulan las normas para el registro de entidades que promuevan y coloque en forma masiva pólizas de seguros.

\subsection{Guatemala}

El artículo 89 de la Ley de la Actividad Aseguradora establece la comercialización masiva de seguros, la cual es reglamentada por Resolución JM $-1-2011$.

En este sentido, la contratación de seguros masivos se realiza a través de personas jurídicas, mediante un contrato de comercialización suscrito con la respectiva aseguradora.

Asimismo, las condiciones de la póliza deben ser redactadas de forma tal que sea fácil la comprensión para el asegurado, y en caracteres visibles aspectos tales como la prima, monto de cobertura, exclusiones, coberturas. Asimismo, se deben contar con mecanismos que faciliten el pago de la prima.

Las pólizas deben ser uniformes, sin condiciones especiales; y los asegurados, deberán ser personas naturales.

Al igual que en la mayoría de países donde hay regulación sobre comercialización masiva de seguros, el asegurador debe responder por los errores que en la suscripción cometa el comerciante, asimismo debe capacitarlo, y las primas que se reciban se entienden pagadas al asegurador. 


\subsection{Argentina}

En Argentina, la permisión para la comercialización masiva de seguros es un poco distinta a la de los demás países; en lugar de permitir la comercialización masiva de seguros y establecer la permisión especial de venta a los comerciantes de bienes y servicios, o a las entidades financieras; lo que se hizo, por medio del decreto 855/1994 del Poder Ejecutivo Nacional, fue liberar las restricciones a la comercialización de seguros contenidas en la ley 22.400, para aquellos seguros que se ofrezcan al público en general y tengan por objeto coberturas de uso generalizado.

Esto nos lleva a concluir que los seguros que ha determinado la Superintendencia de Seguros que sean ofrecidos al público en general y que tienen por objeto coberturas de uso generalizado (automotores y vehículos remolcados, combinado familiar, incendio de casas de familia, caución para alquiler de inmuebles, cobertura individual y temporaria del ramo vida, sepelio, accidentes personales), pueden ser comercializados por asesores de seguros, bancos, establecimientos de comercio, y por personas naturales.

\subsection{España}

La Ley 26 de 2006 regula la mediación de seguros y reaseguros privados, regulando lo establecido en la Directiva 2002/92 del Parlamento Europeo y del Consejo de la Unión Europea. En esta se establecen los principios de la mediación en este país, excluyendo expresamente los seguros con primas anuales inferiores a 500 euros $^{2}$, los cuales no se sujetan a los estándares de la distribución tradicional de seguros. Así mismo se regula de manera expresa el canal de bancaseguros, permitiendo la utilización de todo el canal de estas entidades para la distribución de seguros, no obstante cada aseguradora deberá contar con un operador único de banca-seguros, es decir, desde la ley se establece una exclusividad para la aseguradora con el establecimiento de crédito $^{3}$.

En este momento cursa un anteproyecto de Ley de distribución de seguros y reaseguros privados, con el fin de ajustar la regulación española

2 Ley 26 de 2006, artículo 3, numeral 2, literal d.

3 Ley 26 de 2006, artículo 25. 
a lo dispuesto en la Directiva 2016/97, buscando igualar la información y la protección entre los diversos canales de distribución, siempre y cuando la prima supere un monto de $\$ 600$ Euros al año ${ }^{4}$. Frente a los operadores de Banca-seguros, el principal cambio es que desaparece la exclusividad que tiene la entidad aseguradora con el operador, pudiendo de esta forma crear alianzas con distintos operadores para la distribución de este tipo de seguros 5 .

\subsection{Conclusión}

Podemos afirmar, de acuerdo con este panorama regulatorio internacional, que hay una tendencia desintermediadora en la comercialización de seguros, en búsqueda de una mayor inclusión del sector asegurador, y a su vez que este pueda generar una mayor penetración en el PIB de los países, el cual es bastante bajo en nuestros países latinoamericanos ${ }^{6}$.

No obstante lo anterior, ello no quiere decir que cualquier persona natural o jurídica pueda comercializar cualquier tipo de seguro, encontramos que estos deben ser productos que cumplan con las características de masividad, es decir, deben ser productos sencillos, estándares y algunas veces con montos de primas especialmente regulados, y en algunos casos con formación especial para la comercialización de estos productos en donde se garantice la debida asesoría a los consumidores financieros ${ }^{7}$.

4 Directiva (UE) 2016/97, considerando No. 15, en donde se indica: "La presente Directiva no se debe aplicar a las personas que ejerzan la distribución de seguros como actividad auxiliar cuando la prima no exceda de un determinado importe y los riesgos asegurados estén limitados. Tales seguros pueden ser complementarios de un bien o servicio, también en relación con el riesgo de no utilización de un servicio cuyo uso esté previsto en un determinado momento, como un viaje en tren o un abono de gimnasio o de temporada teatral, y otros riesgos vinculados con un viaje, como la cancelación de este o la pérdida del equipaje. No obstante, para garantizar que se observa siempre un grado adecuado de protección del consumidor en relación con la actividad de distribución de seguros, cualquier empresa o intermediario de seguros que lleve a cabo la actividad de distribución a través de un intermediario de seguros complementarios que esté exento de los requisitos establecidos en la presente Directiva debe garantizar que se cumplen determinados requisitos básicos, tales como la comunicación de su identidad y la manera de presentar una reclamación, y que las exigencias y necesidades del cliente se toman en consideración.

5 Martínez Fernández, Virginia (2017). Anteproyecto de Ley de Distribución de Seguros y Reaseguros Privados. Recuperado el 28 de marzo de 2017. https://www.hoganlovells.com/es/publications/ anteproyecto-de-ley-de-distribucion-de-seguros-y-reaseguros-privados

$6 \quad 2.86 \%$ en el 2015. Contreras, Claudia (2016). Hay mercado potencial de US\$398 millones en primas de seguros en América Latina. Recuperado el 28 de marzo de 2017. http://www.estrategiaynegocios. net/finanzas/1002507-330/seguros-crecer\%C3\%A1n-6-en-am\%C3\%A9rica-latina-en-2016

7 Circular Externa 049 de 2015. Superintendencia Financiera de Colombia. 


\section{CAPÍTULO 2 \\ PANORAMA COLOMBIANO}

Dentro del panorama colombiano encontramos avances regulatorios que permiten la democratización del contrato de seguro, en donde cada vez una mayor cantidad de personas, de todos los estratos socioeconómicos han tenido mayores posibilidades de adquirir un seguro, no solo por sus costos, sino también por la posibilidad de adquirirlo en una gama de lugares cada vez más amplia. No obstante consideramos que falta regulación que permita acceder a formas de aseguramiento sencillas y asequibles, especialmente en las zonas más alejadas del país, ello sin desconocer los pasos que en la materia se han hecho, así como la buena labor que ha sido desarrollada por parte del Gobierno Nacional y de los reguladores.

En este capítulo revisaremos, las normas que regulan la actividad de la intermediación en seguros en Colombia, en el siguiente orden: (i), el desarrollo de la regulación en uso de red (ii), las nuevas posibilidades que se abren con la incorporación de los corresponsales en seguros (iii), así como algunos casos de venta directa por parte de las compañías y (iv), para luego concluir con los retos que visualizamos.

\subsection{Normas que regulan la actividad de intermediación en seguros en Colombia}

El numeral $2^{\circ}$, del artículo $5^{\circ}$, del Estatuto Orgánico del Sistema Financiera, establece quiénes son intermediarios de seguros, indicando para el efecto, que los intermediarios son los corredores, agencias y agentes. Asimismo, su organización, control y vigilancia se encuentra regulada en el Capítulo XII del mismo estatuto, y por el Libro 30, del Título 1, del Capítulo 1, de la Parte 2, del Decreto 2555 de 2010.

En relación con esta última norma, se destaca la regulación de "personas autorizadas" estableciendo que "la actividad de intermediación de seguros y reaseguros está reservada a las sociedades corredoras, a las sociedades corredoras de reaseguros, a las agencias colocadoras de seguros y a los agentes colocadores de pólizas de seguros, de acuerdo con su especialidad". No obstante punto seguido establece que " $\mathrm{La}$

8 Decreto 2555 de 2010, artículo 2.30.1.1.2. 
actividad de los intermediarios de seguros y reaseguros no inhabilita a las entidades aseguradoras para aceptar y ceder riesgos directamente, sin la intervención de los intermediarios".

Por su parte el numeral $2^{\circ}$, del artículo 188 del EOSF$^{9}$ establecía la prohibición expresa de pagar cualquier tipo de remuneración por intermediación en seguros a personas distintas a los corredores, agentes o agencias. No obstante esta norma fue derogada expresamente por el artículo 101 de la Ley 1328 de 2009, con lo cual se abrió la posibilidad de alianzas distintas para las compañías de seguros, tales como acuerdos con retailers, empresas de servicios públicos, empresas de ventas por catálogo, entre otras.

\subsubsection{Desarrollo Normativo: De los Bancaseguros al Uso de Red}

\subsubsection{Uso de Red}

La posibilidad de utilizar las redes de los establecimientos de crédito, por parte de las compañías de seguros, se ve regulada por primera vez en Colombia en el artículo 5 del Decreto 2423 de $1993^{10}$, el cual permitió que mediante un contrato celebrado entre los establecimientos de crédito y las aseguradoras, éstas colocaran contratos de seguro voluntarios de características masivas.

No obstante lo anterior, la Federación Nacional de Productores de Seguros -FENALPROSE- demandó la declaratoria de nulidad de este artículo $^{11}$, al considerar que la actividad de intermediación, entendida como tal, la realizada por agentes, agencias y agentes, el Gobierno Nacional carecía de facultades regulatorias para la expedición de esta

9 “(...). 2. Prohibición relativa al pago de comisiones u otras remuneraciones. Se prohibe a las compañias de seguros abonar o pagar comisiones, o, en general, emplear cualquier otra modalidad de remuneración por la labor de intermediación a personas distintas de las sociedades corredoras, agencias o agentes autorizados de acuerdo con este Estatuto (...).”.

10 Artículo $5^{\circ}$ : A partir de la entrada en vigencia del presente Decreto, los establecimientos de crédito podrán colocar directamente seguros en sus redes de oficinas, previa la celebración de los convenios a que haya lugar y siempre y cuando sean pólizas que, a juicio de la Superintendencia Bancaria, tengan características y condiciones que las hagan idóneas para su comercialización masiva.

11 Consejo de Estado, expediente 3110 de 1994, MP Libardo Rodríguez Rodríguez. 
nueva forma de comercialización de seguros, al tratarse la actividad de los intermediarios, una actividad especializada.

Frente a los argumentos de la demanda, se opuso el Ministerio de Hacienda y Crédito Público, la Unión de Aseguradores Colombianos -FASECOLDA-, la Asociación Bancaria y de Entidades Financieras de Colombia -ASOBANCARIA-, la Superintendencia Bancaria (hoy Superintendencia Financiera de Colombia), y TECSEFIN S.A., básicamente argumentando que el Gobierno Nacional contaba con plenas facultades para la expedición de la norma acusada, así como que la actividad de los intermediarios no es una actividad especializada, y que la labor de las entidades crediticias no era propiamente de intermediación, por lo que no estaba encomendándoles las labores que se demandaban propias de los intermediarios ${ }^{12}$.

No obstante estas oposiciones, el Consejo de Estado declaró la nulidad del artículo $5^{\circ}$ del Decreto 2423 de 1993, al considerar que la norma "sí viola las normas consideradas como infringidas, pues encontrándose establecido que la colocación de seguros es el resultado final que pretenden los intermediarios a través de su actividad de promoción y ofrecimiento, actividad reservada a estos, mal pueden los establecimientos de crédito ejercerla, cuando corresponde a los intermediarios de seguros como entidades especializadas que son" ${ }^{13}$.

No obstante, no puede desconocerse el valor del decreto, y de su posterior sentencia de nulidad, dado que el primero introdujo el concepto de conceptos de masa, y a su turno, la sentencia de nulidad aportó reflexiones sobre el sistema de contratación y su legalidad, lo cual permitió posteriormente, desarrollos legislativos en relación con esta modalidad de contratación de seguros ${ }^{14}$.

12 Se destaca, que la oposición a la demanda por parte del Ministerio de Hacienda, fue la siguiente: "La Banca-Seguros consiste en que el establecimiento de crédito coloca entre sus clientes la póliza de seguros estandarizada (jamás adaptadas a las necesidades particulares del asegurado), ya preparada por la compañia de seguros y autorizada por la Superintendencia Bancaria. Su papel se limita a diligenciar en nombre del asegurado y los datos mínimos de la póliza según la instrucción que previamente le ha impartido la compañia de seguros. Por eso cabe preguntarse, dónde está la intermediación en este proceso?".

13 Consejo de Estado, expediente 3110 de 1994, MP Libardo Rodríguez Rodríguez.

14 Diez años de la ley 389 de 1997. En: Ponencia del Capítulo de Medellín. Memorias del XXV Encuentro Nacional, Aspectos sustantivos y procesales del contrato de seguros. ACOLDESE, Medellín, Colombia. (p. 86) Octubre de 2007. 
A su turno, la Ley 389 de 1997, y su posterior decreto reglamentario 1367 de 1998, por fin lograron la implementación del modelo de Bancaseguros en Colombia, ampliando el modelo que se tenía hasta la fecha, y consagrado en el artículo 93 del EOSF, del uso de red de oficinas. Bajo la nueva reglamentación, la aseguradora podía no solo utilizar las oficinas de los establecimientos de crédito, sino también sus empleados y sus sistemas de información con el fin de comercializar los productos permitidos con la nueva regulación ${ }^{15}$.

Dentro de ésta se establece que los productos deben cumplir con las características de universalidad, sencillez y estandarización, y ser susceptibles de comercialización masiva por no exigir condiciones específicas en relación con las personas o intereses asegurables. Asimismo se establecieron los ramos de los productos que podían ser comercializados por este canal, y las condiciones del contrato entre la aseguradora y el establecimiento de crédito.

Esta norma permaneció inalterada hasta el año 2012, cuando se permitió que las compañías aseguradoras celebraran también contratos de uso de red con otras entidades vigiladas por la $\mathrm{SFC}^{16}$, más allá de los establecimientos de crédito.

El 2015 fue otro año importante para estos canales de distribución, pues se actualizaron los ramos que pueden ser comercializados ${ }^{17}$, y se permite su colocación no sólo a personas naturales, sino también a personas jurídicas ${ }^{18}$, autorizándose también su distribución por medio de las Sociedades Especializadas en Depósitos y Pagos Electrónicos (SEDES) ${ }^{19}$.

15 Diez años de la ley 389 de 1997. En: Ponencia del Capítulo de Medellín..., cit., (p. 86 y ss.)

16 Decreto 2673 de 2012, artículo 3. "Podrán ser igualmente comercializados mediante la red de las sociedades de servicios financieros, las sociedades comisionistas de bolsa de valores, las comisionistas independientes de valores, las sociedades administradoras de inversión y las sociedades administradoras de depósitos centralizados de valores, los ramos de seguros de que trata el presente capítulo bajo los requisitos y condiciones alli previstos".

17 Decreto 034 de 2015, artículo 2. "El listado completo de los ramos a comercializar de acuerdo a esta norma, es: Seguro Obligatorio de Accidentes de Tránsito. - Seguro de automóviles. - Seguro de exequias. - Accidentes personales. - Seguro de desempleo. - Seguro educativo. - Vida individual. Seguro de pensiones voluntarios. - Seguro de salud. - Seguro de responsabilidad civil. - Seguro de incendio. - Seguro de terremoto. - Seguro de sustracción. - Seguro agrícola. - Seguro del hogar.Seguro colectivo de vida. - Seguro vida grupo".

18 Decreto 034 de 2015, articulo 1. El artículo $1^{\circ}$ del decreto 034 de 2015, modifica el artículo 2.31.2.2.1 del decreto 2555 de 2010, eliminando la palabra "naturales" de las características de universalidad y sencillez, con lo que se permite que los productos que se comercializan mediante uso de red, puedan cubrir riesgos de toda clase de personas.

19 Decreto 1491 de 2015, artículo 6. 


\subsubsection{Características}

Tal y como se anunciaba en líneas precedentes, los productos voluntarios comercializados mediante contrato de uso de red con entidades vigiladas por la Superintendencia Financiera de Colombia, deben contener unas características propias para ser comercializados masivamente, estas son:

1. Universalidad. Es la característica consistente en que las pólizas de los ramos de seguros autorizados a continuación, deben proteger intereses asegurables y riesgos comunes a todas las personas.

2. Sencillez. Es la característica consistente en que las pólizas de los ramos de seguros autorizados, sean de fácil comprensión y manejo para las personas.

3. Estandarización. Es la característica consistente en que el texto de las pólizas de los ramos de seguros autorizados, sea igual para todas las personas según la clase de interés que se proteja y por lo tanto, no exijan condiciones específicas ni tratamientos diferenciales a los asegurados.

4. Comercialización masiva. Es la distribución de las pólizas de los ramos autorizados a través de la red de los establecimientos de crédito y de corresponsales, siempre que cumpla con las condiciones o requisitos antes señalados" ${ }^{20}$.

\subsubsection{Ramos}

En principio la regulación de este canal solo permitió la comercialización de los siguientes ramos ${ }^{21}$ :

- Seguro Obligatorio de Accidentes de Tránsito

- Integral Familiar (multiriesgo familiar o multiriesgo residencial).

- Multiriesgo personal.

- Seguro de automóviles.

20 Decreto 2555 / 2010, artículo 2.31.2.2.1

21 Decreto 1367 de 1998, artículo 2. 
- Seguro de exequias.

- Accidentes personales.

- Seguro de desempleo.

- Seguro educativo.

- Vida Individual.

- Seguro de pensiones voluntarios.

- Seguro de salud

Este listado permaneció inalterado hasta el año 2015, cuando, casi 17 años después de su expedición, se expidió del decreto 034 del año en mención, ampliando los ramos susceptibles de ser comercializados por este canal, ofreciendo oportunidades de penetración y de inclusión al sector asegurador, quedando hoy en día los siguientes ${ }^{22}$ :

- Seguro Obligatorio de Accidentes de Tránsito.

- Seguro de automóviles.

- Seguro de exequias.

- Accidentes personales.

- Seguro de desempleo.

- Seguro educativo.

- Vida individual.

- Seguro de pensiones voluntarios.

- Seguro de salud.

- Seguro de responsabilidad civil.

22 Se incluye la lista completa, pues además de adicionar ramos, también se modificó la denominación de los mismos adecuándolo al listado de ramos autorizados consagrada en la Circular Básica Jurídica 029 de 2014 de la Superintendencia Financiera de Colombia. 
- Seguro de incendio.

- Seguro de terremoto.

- Seguro de sustracción.

- Seguro agrícola.

- Seguro del hogar.

- Seguro colectivo de vida.

- Seguro vida grupo.

\subsubsection{Otras formas de comercialización}

Si bien el esquema colombiano se ha reglamentado mediante contratos de uso de red para la comercialización de pólizas individuales, no dejan de encontrarse esquemas alternativos que buscan eludir el cumplimiento de requisitos normativos, tal como los esquemas donde se estructura la comercialización mediante pólizas colectivas, con el fin, quizás, de evadir las restricciones regulatorias dadas por las características de las pólizas, limitación de ramos, y forma de estructuración del negocio.

No obstante hay quienes abogan por su validez, a falta de una prohibición expresa, y no estar realizándose colocación, ni promoción del contrato de seguro al ya existir el contrato derivado de la colocación realizada directamente entre aseguradora, y entidad financiera ${ }^{23}$. Frente a este tema la Superintendencia Financiera de Colombia ha sido clara en señalar que solo son viables los esquemas de uso de red autorizados por la ley 389 de 1997, y el artículo 93 del Estatuto Orgánico del Sistema Financiero $^{24}$, es decir, mediante contrato de uso de red, o uso de red de oficinas $^{25}$.

23 Guillermo Rueda, Manuel (1998). La Bancaseguros en Colombia. Revista Fasecolda. - Bogotá : Unión de Aseguradoras Colombianos, 1979- = ISSN 0120-1972. - 01/07/1998 Número 89 - 1998 , p. 28-35. Recuperado el 19 de noviembre de 2016. https://www.fundacionmapfre.org/documentacion/ publico/es/catalogo_imagenes/grupo.cmd?path=1061031

24 Concepto 2010010535-002 del 30 de marzo de 2010. Superintendencia Financiera de Colombia.

25 El uso de red de oficinas es un esquema en donde el establecimiento de crédito le permite a la aseguradora tener un puesto en el establecimiento de crédito. El personal que se utiliza es el de la aseguradora. Al no ser propiamente un esquema de bancaseguros no se aborda en este estudio, así como por su casi nula aplicación en las operaciones entre entidades financieras y aseguradoras. 


\subsubsection{Algunas Cifras}

Del total de la producción de las aseguradoras en América Latina, el 39\% es comercializado por la red de las entidades financieras.

De este $39 \%$, Brasil comercializa casi el $78 \%{ }^{26}$, siendo el $55 \%$ del mercado comercializado por este canal en dicho país ${ }^{27}$.

Colombia tan solo representa el $2.6 \%{ }^{28}$ del mercado de bancaseguros latinoamericano, y el canal bancario representa casi el $20 \%{ }^{29}$ de la colocación nacional de seguros, no obstante para el ramo de vida individual este canal representa el $24 \%$ de la producción ${ }^{30}$. En un mercado de 21.5 billones de pesos ${ }^{31}$, la bancaseguros puede aportar cerca de 4.3 Billones $^{32}$.

En el año de 1998, recién expedido el decreto 1367, se estimaba que había un mercado potencial de 7.2 millones de personas en capacidad de adquirir este tipo de seguros ${ }^{33}$. Hoy se estima que los riesgos asegurados por micro seguros en el país puede ser superior a 7.4 millones $^{34}$, lo cual demuestra un crecimiento exponencial, y la diversificación de canales, como un elemento fundamental para inclusión financiera.

26 Pinzón Fonseca, Daniel Andrés. La Experiencia de América Latina en Bancaseguros. Revista Fasecolda.

27 Pinzón Fonseca, Daniel Andrés y Zarta Arizabaleta, José Fernando. La Oportunidad de Bancaseguros. Revista Fasecolda.

28 Pinzón Fonseca, Daniel Andrés. La Experiencia de América Latina en Bancaseguros. Revista Fasecolda.

29 Fundación MAPFRE. Recuperado el 28 de marzo de 2017. https://www.fundacionmapfre.org/ documentacion/publico/i18n/catalogo_imagenes/grupo.cmd?path=1060534

30 Pinzón Fonseca, Daniel Andrés. La Experiencia de América Latina en Bancaseguros. Revista Fasecolda.

31 Aproximadamente USD7.2 Billones.

32 Aproximadamente USD1.43 Billones.

33 Redacción El Tiempo (1998). Bancaseguros, el nuevo mercado. Recuperado el 28 de marzo de 2017. http://www.eltiempo.com/archivo/documento/MAM-831210

34 Camargo, Andrea; Tatin-Jaleran, Clémence; Furt Goncalves, Leticia Gontijo (2014). Colombia hacia un sector de seguros inclusivo y universal. Recuperado el 28 de marzo de 2017. http://www. bancadelasoportunidades.gov.co/documentos/Publicaciones_banca/diagnostico_microseguros.pdf 


\subsubsection{Seguros de Desgravamen}

En la definición clásica de bancaseguros ${ }^{35}$ habíamos comprendido solo aquellos productos voluntarios comercializados mediante la red de los establecimientos bancarios, no obstante hoy en día dentro de las estructuras de las compañías de seguros, las áreas de bancaseguros se ocupan de estos productos voluntarios, pero también de la contratación de las pólizas colectivas que hacen las entidades para respaldar las obligaciones de sus deudores, bien sea mediante pólizas de vida, o de daños ${ }^{36}$. A estos seguros nos referiremos como seguros de desgravamen.

En las líneas que siguen veremos el desarrollo normativo de estos seguros en Colombia.

\subsection{Decreto 384 de 1993}

Si bien fue una norma que puso orden al proceso de contratación de seguros por parte de las entidades financieras por cuenta de sus deudores, con el fin de garantizar las obligaciones que se tuvieran con ellas, fue una norma simple, que con el fin de dar transparencia a las aseguradoras, y a los consumidores, estableció los siguientes principios:

- Igualdad de Acceso

- Igualdad de Información

- Objetividad en la Selección del Asegurador

- Unidad de Póliza

35 Refiriéndose a la denominación de bancaseguros para este tipo de seguros, el profesor Carlos Ignacio Jaramillo indica: "Aun cuando desde hace varias décadas las compañías de seguros colombianas habían mostrado cierto interés en el corredor bancario para la comercialización de algunos seguros de personas, el cual en todo caso era muy específico ('seguro de desgravamen'), lo cierto es que, en estricto sentido, a comienzos de la década de los años noventa comenzó a desarrollarse un canal alternativo, llamado comercialmente como 'Banca-seguros', así esa no haya sido el nomen legal reconocido primigeniamente, según lo mencionaremos más a espacio, por cuanto esta no ha sido, ab initio, una denominación normativa, sino del mercado, fruto de acuerdos de colaboración empresarial y de puntuales alianzas estratégicas (contratos atípicos), llamados a gobernar la relación 'banco' ‘compañía' de seguros (Decreto 1367/98). Artículo en Homenaje al Profesor Andrés Ordoñez Ordoñez, 2017.

36 Referenciación dada por Martinez Franco, Juan Carlos. Gerente de Bancaseguros. Seguros de Vida Suramericana S.A., Seguros Generales Suramericana S.A. 
Esto se hacía mediante un procedimiento licitatorio que debía repetirse máximo cada tres años, no obstante la entidad bancaria podía escoger cualquiera de las entidades que se presentara a la convocatoria, es decir, no se regulaba un método para la selección de la aseguradora.

\subsection{Decreto 673 de 2014}

Si bien el decreto 384 de 1993 buscó dar transparencia al procedimiento de selección de la aseguradora con la cual se garantizaban los créditos que se tenían con los deudores de los establecimientos bancarios, al no haber criterios de selección definidos la adjudicación terminaba siendo a la entidad de preferencia del establecimiento, y la posibilidad por parte del consumidor de escoger la de su preferencia era bastante limitada.

La Ley 1328 de 2009 se consagró como la ley de protección de los consumidores financieros, en donde dentro de sus principio orientadores se encuentran la debida diligencia, libertad de elección, transparencia e información cierta, suficiente y oportuna, manejo adecuado de los conflictos de interés, entre otros ${ }^{37}$. Así mismo estaba viendo ya en este momento el Ministerio de Hacienda y Crédito Público de Colombia, que la contratación de seguro por cuenta de los deudores podía generar sobre costos para los consumidores, y que era necesario proteger y garantizar la libertad de contratación por parte de los tomadores de seguros ${ }^{38}$.

De acuerdo con lo anterior era necesario adecuar la regulación vigente hasta entonces para respaldar las obligaciones de los deudores con las entidades financieras, por lo que se expidió el Decreto 673 de 2014, el cual se dividió en dos partes:

\subsection{Licitación de Seguros Diferentes a los Asociados a Créditos} con Garantía Hipotecaria o Leasing Habitacional. Este procedimiento en gran medida permaneció inalterado, sin reglas sobre el procedimiento y la selección de la aseguradora, pero continuando los postulados básicos para el procedimiento licitatorio, donde encontramos de nuevos:

37 Ley 1328 de 2009, artículo 3.

38 Considerandos del Decreto 673 de 2014. 
- Igualdad de Acceso

- Igualdad de Información

- Objetividad en la Selección del Asegurador

- Elección de la Aseguradora por parte del Deudor

- El procedimiento ahora debe realizarse cada dos años.

\subsection{Licitación de Seguros Asociados a Créditos con Garantía} Hipotecaria o Leasing Habitacional. Se adoptan los mismos principios orientadores, no obstante, se realizan unas modificaciones dadas las particularidades del procedimiento adoptado a los seguros asociados a créditos con garantía hipotecaria:

- Igualdad de acceso: De acuerdo con éste principio, todas las Compañías Aseguradoras en Colombia, que cuenten con autorización para la explotación del ramo a licitar (incendio y terremoto, y vida), y que posean una calificación de riesgo igual o superior a "A", pueden concurrir a éstas licitaciones, para participar en ellas.

- Igualdad de información: A través de éste principio se establece, que las instituciones financieras que lleven a cabo licitaciones, deben informar a todas las Compañías Aseguradoras que concurran, y en igualdad de condiciones, toda la información relacionada con la licitación respectiva, incluyendo también, información relacionada con la siniestralidad de la cartera.

En relación con la segmentación de la cartera resaltamos, que de acuerdo con lo que dispone el Decreto, es posible realizar la segmentación de la misma, cuando con base en la distribución de la frecuencia y de la severidad de los siniestros, existan criterios objetivos y razonables para hacerlo, y los mismos sean reconocidos también por la Superintendencia Financiera de Colombia.

- Libertad de elección: Éste principio propende porque el deudor asegurado pueda contratar con otra compañía aseguradora, siempre y cuando se cumplan con las condiciones del seguro respectivo sean al menos iguales, a las contenidas en el pliego de condiciones de la licitación. 
Asimismo se establece que en el evento que la institución financiera rechace la póliza de seguro que el deudor asegurado decidió contratar, se establece la obligación de informar tal situación al deudor, dentro de los de los diez (10) días hábiles siguientes contados a partir de la fecha de recibo de la solicitud.

2.1.1.6.2.2.1. Aspectos a tener en cuenta en el procedimiento. Como lo mencionamos, el procedimiento fijado es de obligatoria observancia para aquellos casos en los cuales se realiza licitación de seguros asociados a créditos con garantía hipotecaria o leasing habitacional.

Se deben tratar de seguros colectivos, no individuales.

La licitación debe tener una duración máxima de dos años, contados desde la fecha de la adjudicación. En este punto resaltamos que la norma ha dispuesto que si durante la vigencia del respectivo contrato de seguro, el patrimonio técnico de la aseguradora se llegare a encontrar por debajo de los niveles mínimos legales fijados por la Superintendencia Financiera de Colombia, o se llegaren a incumplir los requisitos de admisibilidad fijado en el pliego de condiciones, la adjudicante (institución financiera) podrá terminar de manera unilateral el contrato en mención, Para el efecto, se deberá dar un preaviso mínimo de noventa (90) días calendario. Lo anterior con el propósito de abrir un nuevo proceso licitatorio.

Se establece además, el deber de informar al deudor acerca del seguro que se ha contratado, así como si el deudor ya recibió la póliza. En este sentido, la institución financiera contará con quince (15) días hábiles para entregar a su deudor, una copia de la póliza que le entregó la respectiva compañía aseguradora, así como realizar la publicación en su página de internet, de los términos y condiciones del seguro contratado.

El pliego de condiciones a través del cual se lleva a cabo todo el proceso de licitación, de acuerdo con éste Decreto, es una oferta de contrato. En este sentido, cada postura implica la celebración de un contrato condicionado a que no exista una postura mejor.

Se adopta, como parte del procedimiento fijado, que las correspondientes instituciones financieras no reciban los pagos por concepto de 
primas. El Decreto lo establece como una prohibición de pagos a favor de la correspondiente institución financiera. En este sentido, el Decreto establece que no podrá fijarse el pago de comisiones, participación de utilidades o remuneración de cualquier tipo a favor de la institución financiera otorgante del crédito.

En cuanto a los aspectos propios del contenido del pliego de condiciones:

El Decreto señala, que como mínimo, dentro del pliego de condiciones se debe incorporar:

Aspectos relacionados con los elementos esenciales de los seguros obligatorios de incendio y terremoto. Esto aplica en el evento que las coberturas sean incluidas en la licitación.

La inclusión de requisitos de admisibilidad adicionales, que cumplan con los criterios definidos por parte de la Superintendencia Financiera.

La tarifa que la institución financiera convocante ha determinado por cuenta del servicio de recaudo de las primas de seguros licitados. En este caso se ha dispuesto que la institución financiera cuente con un plazo máximo de treinta (30) días calendario, contados desde la fecha del respectivo recaudo, para realizar la entrega de tales recursos a la compañía aseguradora correspondiente.

Igualmente, de acuerdo con lo dispuesto en el artículo $1071^{39}$ del Código de Comercio, se señala que el pliego de condiciones debe incorporar una cláusula a través de la cual se indique la imposibilidad de revocatoria unilateral de la póliza.

También, el Decreto establece que se fije cualquier otro contenido al pliego de condiciones que determine la correspondiente institución financiera, así como la inclusión de cualquier otro requisito que estime la Superintendencia Financiera.

39 El artículo 1071 del código de comercio permite, por regla general, la revocación unilateral del contrato de seguro por cualquiera de las partes contratantes. Código de Comercio, artículo 1071. 
Asimismo, el pliego de condiciones es de carácter gratuito para todas aquellas instituciones financieras interesadas en participar.

Del proceso de licitación en sí mismo:

Igualmente se establece que el proceso de licitación iniciará mediante comunicación escrita dirigida al representante legal de todas las compañías aseguradoras autorizadas para operar en los ramos a licitar. Asimismo se señala que el proceso de licitación deberá llevarse a cabo, como mínimo noventa (90) días calendario antes de que expiren los contratos existentes, y aquellos celebrados con las aseguradoras adjudicatarias de la licitación anterior.

El pliego de condiciones podrá ser objeto de modificación. En este sentido se dispone que las compañías aseguradoras cuenten con un plazo máximo e improrrogable para formular preguntas sobre el pliego de condiciones.

Las preguntas que se hayan formulado, y su correspondiente respuesta, la institución financiera debe publicarlas en un lugar destacado en su página de internet.

Una vez se hayan resuelto las inquietudes, así como que las mismas se hayan publicado, las Compañías Aseguradoras interesadas en licitar, deben presentar sus posturas en sobre cerrado. De acuerdo con esto, la presentación de una postura vincula a la respectiva compañía aseguradora durante el período comprendido entre la presentación de la postura y la adjudicación de la licitación.

Destacamos igualmente, que las Compañías Aseguradoras interesadas en participar en el respectivo proceso de licitación, deben presentar sus ofertas como una tasa de prima mensual incluyendo el IVA, expresada en porcentaje del monto asegurado de los riesgos que se licitan.

Presentadas las posturas, la institución financiera cuenta con un plazo para adjudicar la licitación. La adjudicación se debe realizar en audiencia pública con la apertura de los sobres cerrados, y la lectura de todas las propuestas. Y la adjudicación de la licitación se hará a la propuesta 
que presente la postura con el menor precio de prima de seguro para el deudor, incluyendo la comisión del corredor de seguros. Igualmente se establece la participación de figuras como la de la Defensoría del Consumidor Financiero, en el sentido de que el Defensor del Consumidor Financiero de la entidad licitante deberá asistir a la audiencia pública, y levantar un acta de dicho proceso de adjudicación.

En el evento que se presente empate en posturas, de acuerdo con lo que dispone el Decreto, la institución financiera respectiva debe elegir la postura que primero haya recibido.

Por último se dispone que una vez se haya adjudicado la licitación, le corresponde a la institución financiera publicar los resultados y el acta de adjudicación en su página de internet.

A septiembre del 2015 el crecimiento de las primas de los seguros de vida grupo han crecido 13\%. Producto de la expedición de 673 del 2014, el cual reglamenta la contratación de seguros de vida vinculados a créditos hipotecarios, se ha presentado una migración de primas de vida grupo hacia vida individual. Sin este cambio en el mercado, el crecimiento del ramo de vida grupo hubiera sido de $17 \%$ respecto a septiembre del $2014^{40}$.

\subsection{Decreto 1534 de 2016}

El propósito de éste nuevo Decreto fue realizar ajustes en materia de igualdad de acceso para la contratación, a través del pliego de condiciones e información del proceso, a través de etapas más claras dentro del proceso licitatorio, con el fin de otorgar mayor transparencia del mismo ${ }^{41}$.

Las principales modificaciones a destacar en esta nueva regulación son las siguientes:

40 Fasecolda en acción (2016). Retos y oportunidades de los seguros de vida grupo e individual. Recuperado el 28 de marzo de 2017. http://www.fasecolda.com/index.php/sala-de-prensa/ noticias/2016/febrero/accion-febrero-11-2016/

41 URF (2016). Documento técnico: Licitación de seguros asociados a créditos con garantía hipotecaria o leasing habitacional. Unidad de regulación Financiera. Recuperado el 28 de marzo de 2017: http:// www.urf.gov.co/urf/ShowProperty?nodeId=\%2FOCS\%2FP_MHCP_WCC-041662\%2F\%2FidcPrim aryFile\&revision=latestreleased 
Con la norma actual (esto es, el Decreto 673 de 2014), los requisitos de admisibilidad que se incorporen en el pliego de condiciones deben atender criterios técnicos relacionados directamente con la prestación del servicio. En cambio, de acuerdo con éste nuevo Decreto, los requisitos de admisibilidad deben atender criterios técnicos que se encuentren relacionados con el seguro, que sea objeto de licitación.

Asimismo, éste nuevo Decreto de cara a la disposición actual, adiciona que en los extractos o estados de cuenta del deudor se deberá informar el resultado de la licitación, así como el derecho que tiene de escoger otra Compañía Aseguradora.

Otro aspecto adicional que trae éste nuevo Decreto es que el costo del servicio de recaudo será reconocido a la correspondiente institución financiera por parte de la compañía aseguradora, y no estará permitido el pago directo del servicio de recaudo a la institución financiera, por parte del deudor.

También, con ésta nueva norma se fija una serie de etapas para llevar a cabo el estudio y modificación del pliego de condiciones, y de los requisitos de admisibilidad. Aspecto que no se encontraba expresamente definido en el Decreto 673.

La presentación de posturas, de acuerdo con éste nuevo Decreto, se hará dentro del plazo que para el efecto señale la Superintendencia Financiera.

Así mismo, precisa que se adjudicará la licitación a la compañía aseguradora que presente la postura con la menor tasa de prima de seguro para el deudor. Según esto, y teniendo en cuenta lo que se señala en el Decreto 673 de 2014, la licitación se adjudica al que presente la postura con el menor precio de prima de seguros.

Este decreto entró en vigencia el primero de marzo de 2017.

\subsubsection{Apertura a la Inclusión Financiera}

Si bien se habían dado pasos importantes para que se produjera una verdadera inclusión financiera, era necesario establecer alianzas entre 
el sector asegurador y los distintos actores del sector productivo, más allá de las entidades financieras, no obstante se encontraban barreras regulatorias que dificultaban estos acuerdos.

La ley a través de la cual se expidió el Plan Nacional de Desarrollo 2010 - 2014, dispuso expresamente que hace parte integrante de ésta, el documento, "Bases del Plan Nacional de Desarrollo 2010-2014 Prosperidad para Todos" $"$.

En el documento se destaca, como apoyo trasversal a la competitividad el acceso a los servicios financieros, resaltado como en el pasado reciente se han adoptado medidas con el fin de aumentar el acceso de la población a servicios financieros formales, basándose en la relación positiva que presenta el nivel de acceso a estos servicios con el crecimiento económico, y específicamente los efectos que se presentan con la reducción de los niveles de desigualdad y de pobreza ${ }^{43}$.

No obstante el avance referido, el Gobierno Nacional consideró en este momento que había factores que distorsionaban y dificultaban la prestación eficiente de servicios financieros a toda la población, y que había condiciones que afectaban la permanencia de oferta financiera formal en el país, por lo que trazó como propósito implementar estrategias encaminadas a:

- Garantizar la permanencia de oferta financiera formal en aquellos lugares donde se ha logrado ampliar la cobertura,

- Apoyar el acceso al sistema financiero por parte de la población actualmente no bancarizada,

- Profundizar el uso de servicios financieros con la diversificación de productos financieros adecuados para la atención de diferentes segmentos poblacionales, e

- Implementar acciones que garanticen educación económica y financiera de calidad para toda la población ${ }^{44}$.

42 Ley 1450 de 2011, artículo 2.

43 Departamento Nacional de Planeación. Bases del Plan Nacional de Desarrollo 2010-2014. p.p. 131.

44 Departamento Nacional de Planeación. Bases del Plan Nacional de Desarrollo 2010-2014. cit., p.p. 131. 
De acuerdo con lo anterior, el Gobierno Nacional dentro de los "Lineamientos Estratégicos" del Plan Nacional de Desarrollo 20102014 incorporó como prioridad "Garantizar la cobertura del sistema financiero", toda vez que encontró que gran parte de la población de los departamentos de la zona periférica sur y de la Amazorinoquia no contaban con servicios financieros formales. Por ello, se propone darle fuerza a la figura de los Corresponsales No Bancarios (CNB), buscando aumentar el número de operaciones que por ellos se realiza, como el pago de impuestos, el pago de nóminas del sector público, el envío y la recepción de giros internacionales, la compra y pago de la prima de seguros de baja cuantía, y mecanismos que incrementaran la apertura de cuentas de ahorro y trámites de crédito ${ }^{45}$.

Así mismo, al referirse al sector asegurador, encontró necesaria la adopción de estrategias de protección contra eventos catastróficos en donde incluye de forma particular los seguros, pues a pesar de considerarlos como un instrumento para la transferencia de riesgos y la mitigación del impacto de los mismos en el bienestar y las finanzas personales, la población colombiana había mantenido bajos niveles de aseguramiento. Por ello se propuso identificar las medidas necesarias para la promoción del diseño de nuevos productos de seguro dirigidos a reducir la vulnerabilidad de la población ante todo tipo de riesgos ${ }^{46}$.

Asimismo, al analizar la política de desarrollo de los microseguros, vio con preocupación cómo la población de menores ingresos tenía mayor probabilidad de verse afectada por enfermedades, accidentes y desastres naturales, que la población de mayores ingresos, lo que genera que esta parte de la población deba recurrir a mecanismos informales de financiamiento altamente costosos, y/o perder o disminuir sus activos, lo cual aumenta su vulnerabilidad y disminuye las oportunidades de superar la pobreza.

Es así como para el mes de agosto de 2010, el Gobierno Nacional contaba con estudios de "Red Juntos" de acuerdo con los cuales, sólo el $5.2 \%$ de las familias en situación de pobreza extrema y/o desplaza-

45 Departamento Nacional de Planeación. Bases del Plan Nacional de Desarrollo 2010-2014. cit., p.p. 132.

46 Departamento Nacional de Planeación. Bases del Plan Nacional de Desarrollo 2010-2014. cit., p.p. 135. 
miento, declaraban contar con algún tipo de seguro, es por ello que se trazó como objetivo trabajar en la identificación de medidas necesarias para la promoción del diseño de nuevos productos de seguro dirigidos a reducir la vulnerabilidad de la población ${ }^{47}$.

En el mes de julio de 2010 la bancarización de la población adulta se encontraba en el $60,2 \%{ }^{48}$. Finalizando el 2013, ésta se encontraba en el $69.2 \%$, con presencia de cobertura por parte de los servicios financieros formales en el $99.7 \%$ de los municipios del país ${ }^{49}$, gran parte en medida por la promoción política ${ }^{50}$ y normativa ${ }^{51}$ que se le ha dado a la figura de los corresponsales bancarios.

Por su parte, la penetración ${ }^{52}$ del sector asegurador en la economía colombiana en el año 2009 fue del 2.3\% del Producto Interno Bruto (PIB), cuando en Latino América y el Caribe fue del 2.8\%, y en Norte América y Europa fue del 8\%53. En el año 2013 la penetración del sector asegurador colombiano llegó al $2.7 \%{ }^{54}$, constituyéndose éste en un avance importante para el sector, pero aún con mucho por avanzar, pues a pesar de ser política del Gobierno Nacional, la promoción de seguros y microseguros por diversos canales, no se había materializado en ninguna regulación que facilitara una verdadera inclusión en el sector asegurador y permitiera, en consecuencia, cumplir con los objetivos trazados en las Bases para el Plan Nacional de desarrollo 2010-2014.

\subsubsection{Normatividad}

En el 2008, no obstante el crecimiento integral del sistema financiero en el país, el Gobierno Nacional era consciente que era posible lograr

47 Departamento Nacional de Planeación. Bases del Plan Nacional de Desarrollo 2010-2014. cit., p.p. 135.

48 Departamento Nacional de Planeación. Bases del Plan Nacional de Desarrollo 2010-2014. cit., p.p. 131.

49 Arango Arango, Juan Pablo (marzo 20 de 2014). Superintendente Financiero encargad., Documento presentaedo en el V Congreso de Acceso a Servicios Financiero, Sistemas y Herramientas de pago de Asobancaria. Cartagena de Indias, Colombia.

50 Departamento Nacional de Planeación. Bases del Plan Nacional de Desarrollo 2010-2014. cit., p.p. 132.

51 Véase, Decreto 2672 de 2012 del Ministerio de Hacienda y Crédito Público y la Circular Externa 029 de 2013 de la Superintendencia Financiera de Colombia.

52 Es la relación entre las primas emitidas y el Producto Interno Bruto.

53 Departamento Nacional de Planeación. Bases del Plan Nacional de Desarrollo 2010-2014. cit., p.p. 135.

54 Najera, A. (2014). 2013: Un año en transición. FASECOLDA, Edición 255, 2014. 
mayores niveles de penetración, pues se pasó de un $25 \%$ en el 2005 al $31.36 \%$ del PIB, sin embargo, esta cifra presenta una tendencia a la baja en comparación con países como Tailandia (97\%), China (120\%), Malasia (150\%) y Chile (65\%). En este sentido, para el Gobierno Nacional era prioridad lograr mayores niveles de penetración financiera en razón a que consideraba que los países con sistemas financieros pequeños presentan menores niveles de desarrollo, dado el bajo respaldo a la actividad económica que realizan las entidades que conforman el sector financiero. De acuerdo con esto para la Banca de las Oportunidades era política fundamental promover el acceso a servicios financieros de manera viable, a gran escala y con independencia de subsidios estatales, por parte de la población más pobre de Colombia y los sectores productivos más marginados del sector financiero formal (micro y pequeñas empresas). Con base en esto el Gobierno Nacional presentó al Congreso de la República de Colombia, un proyecto de reforma financiera con el fin eliminar las barreras que impedían un desarrollo más profundo de los mercados financieros, dotando a los consumidores de herramientas de protección efectivas al ser consciente de los riesgos que esto podía traer aparejado ${ }^{55}$.

Este objetivo del Gobierno al presentar el proyecto de ley fue ratificado en las distintas ponencias en el curso legislativo, y en consecuencia fue promulgada la ley 1328 de 2009, la cual amplió las facultades de intervención en el sector financiero del Gobierno Nacional desarrolladas en el Estatuto Orgánico del Sistema Financiero, y se consagró como un objetivo de esta intervención la promoción al acceso de servicios financieros y de seguros por parte de la población de menores recursos $\mathrm{y}$ de la pequeña, mediana y microempresa ${ }^{56}$, y fue sin duda alguna, un avance importante en materia de protección al consumidor financiero. Así mismo, se dotó al Gobierno de instrumentos para esta intervención otorgándole la facultad de dictar normas y establecer instrumentos que faciliten el acceso a servicios financieros, de seguros y de aquellos que involucren manejo, aprovechamiento e inversión de recursos captados del público por parte de la población de menores recursos, la pequeña, mediana y microempresa, así como las condiciones y mecanismos que

55 Gaceta del Congreso 138. Proyecto de Ley 282 de 2008 de Cámara. También conocida como la Reforma Financiera del 2009.

56 Artículo 46 del Estatuto Orgánico del Sistema Financiero, modificado por el artículo 23 de la ley 1328 de 2009. 
permitan el desarrollo de estos servicios por parte de las entidades que realizan estas actividades ${ }^{57}$.

\subsection{Corresponsales Aseguradores}

En este entorno jurídico y económico es expedido el decreto 034 de 2015, mediante el cual se le permite al sector asegurador realizar operaciones mediante corresponsales de seguros, con lo cual un tercero, cuya actividad principal no es la comercialización de seguros puede ofrecer y promocionar seguros que cumplan las características de universalidad, sencillez, estandarización, y sean susceptibles de comercialización masiva, para los ramos de SOAT, exequias, desempleo, vida individual, accidentes personales, y agrícola. No obstante se le otorga la facultad a la SFC de incorporar nuevos ramos ${ }^{58}$.

Así mismo los corresponsales tienen también la facultad de recaudar primas, pagar siniestros, y entregar y recibir todo tipo de información para la colocación de estos contratos de seguros, u otros de características no tan uniformes pero en donde pueden ayudar en la gestión para la colocación del seguro ${ }^{59}$.

Con este decreto se actualizó el régimen de corresponsales de las entidades vigiladas por la SFC, permitiendo que también las aseguradoras contaran con corresponsales, pues desde el año $2012^{60}$, las otras vigiladas ya podían contar con esta figura para la realización de algunas de sus operaciones básicas.

La figura fue regulada por la $\mathrm{SFC}^{61}$, en donde además de los ramos ya indicados, se permitió la comercialización para los ramos de hogar, incendio y sustracción.

Así mismo, se regula el régimen de exclusiones que pueden tener estos productos, en donde estas, las exclusiones, deben tener un im-

57 Artículo 48 del Estatuto Orgánico del Sistema Financiero, modificado por el artículo 24 de la ley 1328 de 2009.

58 Artículo 2.36.9.1.18 del decreto 2555 de 2010, adicionado por el artículo 12 del decreto 034 de 2015 .

59 Artículo 2.36.9.1.17 del decreto 2555 de 2010, adicionado por el artículo 11 del decreto 034 de 2015.

60 Decreto 2672 de 2012.

61 Circular Externa 049, del 7 de diciembre de 2016. 
pacto sustancial en la prima, y solo podrán proceder en alguno de los siguientes casos:

- Cuando no sea posible limitar la cobertura mediante la redacción del amparo.

- Cuando el evento a excluir no pueda identificarse mediante los mecanismos de comprobación de asegurabilidad.

Hoy en día encontramos en el mercado seguros desde ochocientos pesos colombianos ${ }^{62}$ por semana, comercializados mediante esta figura en tiendas de barrio, lo que muestra la gran sensibilidad y la apuesta del gobierno nacional y del sector asegurador por promover la inclusión financiera, los microseguros, y cerrar las brechas de pobreza ${ }^{63}$.

\subsection{Venta Directa}

Con el fin de buscar mayor penetración y mejorar sus ingresos, las aseguradoras han sofisticado sus sistemas de venta directa con alianzas que les permiten tener mayor cantidad de clientes en todos los estratos de la población, con productos que se ajustan a las necesidades de cada uno de estos segmentos.

Así pues, se ve un fortalecimiento en los sistemas de venta directa tal como en venta en línea ${ }^{64}$ y call center, así como alianzas con compañías

6230 centavos de dólar aproximadamente.

63 Con acierto el profesor Carlos Ignacio Jaramillo citando a María José Pérez-Fructuoso indica: En tal virtud, los microseguros, encaminados a brindar “...protección a las personas con bajos ingresos contra peligros específicos.... a cambio del pago regular de unas primas proporcionales a la probabilidad y al coste del riesgo que se está cubriendo teniendo en cuenta que, como indica el prefijo micro, las transacciones implicadas en este tipo de operaciones son de tamaño reducido así como las primas que por ellas se cobran....", se caracterizan, por naturaleza, por “...la sencillez en la estructura de los productos de microseguro en lo referente al diseño del producto, condiciones de suscripción, cobro de primas, cláusulas y liquidación de siniestros derivada, en su mayor parte, de la escasez de datos actuariales con los que realizan los cálculos".

No es pues fortuito, como lo refrenda la profesora citada, que "Los clientes habituales del seguro tradicional viven en entornos con un nivel de riesgo bajo en los cuales está asentada la cultura aseguradora y disponen de ingresos medios/altos. Los compradores de los productos de microseguro en cambio, están sujetos a circunstancias geográficas, sociales, y culturales con una elevada vulnerabilidad, y por tanto con un nivel de riesgo elevado, y como consecuencia del escaso desarrollo de los países en los que habitan presentan un pobre conocimiento del mercado asegurador". Artículo en Homenaje al Profesor Andrés Ordoñez Ordoñez, 2017.

64 Suraenlinea.com Recuperado el 28 de marzo de 2016: https://www.suraenlinea.com/home 
de venta por catálogo ${ }^{65}$ y con compañías de comercio al por menor en grandes superficies ${ }^{66}$.

Tal y como lo habíamos anunciado en primera parte de este capítulo, la venta directa de seguros por parte de los aseguradores, encuentra soporte legal en el artículo 2.30.1.1.2 del decreto 2555 de 2010, en donde se establece que la actividad de los intermediarios de seguros y reaseguros no inhabilita a las entidades aseguradoras para aceptar y ceder riesgos directamente, sin intervención de estos.

Vale la pena mencionar, que sin razón alguna en la exposición de motivos del proyecto de Ley, la Ley 1700 de 2013 prohibió la comercialización de cualquier producto que sea el objeto principal de cualquier compañía vigilada por la SFC, por medio de compañías de multinivel, con lo cual, alianzas con este tipo de compañías no pueden realizarse en nuestro país ${ }^{67}$.

\section{BENEFICIOS Y RETOS DE LOS NUEVOS CANALES ${ }^{68},{ }^{69}, 70$}

A continuación se resaltan algunos beneficios y retos de los canales no tradicionales, que deben tener en cuenta cada uno de los actores que participan en el negocio:

\subsection{Para los prestadores de la red}

Beneficios

- Fidelización de clientes

\footnotetext{
65 Novaventa, Sura. Recuperado el 28 de marzo de 2016: http://www.novaventasura.com/default.aspx

66 Seguros Éxito. Recuperado el 28 de marzo de 2016: http://www.segurosexito.com/default.aspx

67 Ley 1700 de 2013, numeral $1^{\circ}$, artículo 11.

68 Mora, Christian y Zarruk, Armando. Bancaseguros en la distribución de productos de vida. Revista Fasecolda. Recuperado el 28 de marzo de 2016: https://www.fundacionmapfre.org/documentacion/ publico/i18n/catalogo_imagenes/grupo.cmd?path=1060534

69 Pinzón Fonseca, Daniel Andrés y Zarta Arizabaleta, José Fernando. La Oportunidad de Bancaseguros. Revista Fasecolda.

70 Pinzón Fonseca, Daniel Andrés. La Experiencia de América Latina en Bancaseguros. Revista Fasecolda.
} 
- Optimización de recursos

- Las comisiones por la operación de seguros contribuyen al estado de resultados del prestador; incluso, para el caso de entidades bancarias, pueden compensar la afectación del negocio por la caída de las tasas de interés y la permanente regulación de las comisiones.

Retos:

- Se pueden generar favoritismos hacía los productos que representen mayores beneficios económicos.

- El área de seguros debe ser impecable en el cumplimiento de promesas a los clientes y a la red de sucursales. Una queja no atendida de seguros tiene como consecuencia la pérdida de un cliente del banco.

\subsection{Para las aseguradoras}

Beneficios:

- Se obtiene acceso a una red ya establecida más amplia que la de la aseguradora.

- Se logran mejoras en el recaudo y en los sistemas de información de la aseguradora.

- La comercialización de productos con características que facilitan su distribución masiva permite consolidar una masa crítica de asegurados de una forma más rápida, que traiga consigo mejoras en la siniestralidad sustentadas en la ley de los grandes números, sobre la cual se fundamentan los seguros.

- Fácil acceso a un mercado potencial muy amplio.

- Bajo costo de contacto unitario a potenciales clientes

Retos:

- Se debe tener en cuenta que los prestadores tienen un fuerte poder de negociación, gracias al volumen que operan y que, a diferencia 
del intermediario tradicional, estos no dependen, exclusivamente, del negocio de seguros.

- Limitaciones en la selección de riesgos.

- Diferencias de cultura organizacional entre el prestador de la red y la aseguradora

\subsection{Para los intermediarios}

Reto:

- Los canales modernos son poderosos competidores, por esta razón los canales tradicionales deberán mejorar su oferta de valor tanto para el cliente como para la aseguradora a través de una asesoría profunda y comprometida, que les permita justificar su existencia.

\subsection{Para el cliente}

Beneficio:

- El cliente se ve beneficiado por la facilidad e inmediatez con que ahora puede adquirir los seguros y, también, sus indemnizaciones en caso de presentarse el siniestro.

Reto:

- Es posible que el prestador de la red cobre tarifas elevadas, generando así sobre costos, que finalmente son transferidos al cliente

\section{CONCLUSIONES}

El cambio generacional, y la regulación en materia de información al consumidor financiero ${ }^{71}$, ha generado que los consumidores sean más autónomos e informados, en relación con los productos de aseguramiento, y a quienes les resulta más fácil comparar en las páginas web de las aseguradoras coberturas, exclusiones, derechos, obligaciones, precios, entre otros aspectos, de forma fácil y oportuna.

71 Ley 1328 de 2009, artículos 9 y 10, desarrollados por las Circular Externa 038 de 2011. 
Por su parte, las nuevas tendencias colaborativas de aseguramiento ${ }^{72}$, cada vez más tienden a favorecer la negociación directa entre clientes. Asimismo, las plataformas que administran estas nuevas modalidades, tienden también a favorecer tales negociaciones con los clientes.

Esta situación genera oportunidades de crecimiento importantes para las aseguradoras, pero también riesgos, los cuales deben ser vistos y analizados a partir de su integralidad; esto es, saber que los mismos vienen, así como saber cómo se enfrentan.

En primer lugar, las entidades tienen la posibilidad de ganar nuevas participaciones de mercado, explicado por aquellos clientes que se alejan de los sistemas tradicionales de intermediación, y que buscan formas ágiles, fáciles y económicas de cubrir sus riesgos.

No obstante, estos clientes, no buscan proteger los mismos riesgos tradicionales, es decir, sus necesidades van más allá del aseguramiento de su vehículo o su hogar ${ }^{73}$, pues no son acumuladores, y sus necesidades se basan más en experiencias de vida, como viajes o momentos.

Así mismo se enfrenta el sector asegurador tradicional a la llegada de nuevos competidores, absolutamente digitales, con sistemas de aseguramiento basados en comunidades de riesgo, pero sin regulación prudencial como estructura societaria, vigilancia estatal, márgenes de solvencia, entre otros aspectos, que lo dejan en desventaja regulatoria.

De igual forma no podemos perder de vista la importancia de los nuevos canales y los nuevos productos en la democratización del contratos de seguro, y la consecuente inclusión que ello genera, al respecto el doctor Carlos Ignacio Jaramillo ${ }^{74}$, indica que " $[$ n] en vano, expresamos en precedencia que el canal de la Banca-seguros persigue la democratización del seguro - a la par que los apellidados 'microseguros'-,

72 Fitzgerald, Michael (2015). Friendsurance: Challenging the Business Model of a Social Insurance Startup - A case study.

73 Ver: http://cosas.com.ec/la-generacion-de-la-acumulacion-vs-la-del-disfrute-cuan-ecoamigables-sonlos-millennials/

74 Jaramillo Jaramillo, Carlos Ignacio (2017). Artículo en Homenaje al Profesor Andrés Ordoñez Ordoñez. 
el que no puede ser monopolizado ni por las personas jurídicas, ni por las personas naturales de mayores posibilidades y recursos económicos, motivo por el cual debe cobijar a la clase media y, en lo posible, con arreglo a planes de bajo costo, a clases menos pudientes -o populares-, a consumidores simples, de carne y hueso, no por ello menos urgidos de los beneficios emergentes de un seguro, entendido como un fiable instrumento democrático y económico de apalancamiento social que, de paso, en cierto modo, contribuya a cerrar la brecha existente en materia de clases y estratos sociales, y a un mayor y equitativo acceso a la riqueza, no en pocas ocasiones mal distribuida".

De acuerdo con lo anterior, es importante destacar que no son menores los retos que enfrenta el sector asegurador, con el fin de ganar terreno en nuevos segmentos y con nuevos consumidores, bajo unas condiciones nuevas en colocaciones de seguros, cada vez más de forma directa, y con unos competidores que aún están por conocerse.

Para terminar vale la pena recordar las palabras del profesor Walter Villa Zapata, hace casi ya 20 años ${ }^{75}$, pero que siguen siendo plenamente vigentes:

"Hoy, quienes, como dijo Machado, hicieron camino al andar, como son los agentes de seguro o corredores o productores de seguros, esto es, los que tradicionalmente efectúan función de intermediación entre los asegurables y el asegurador y que forman parte de la historia del seguro en todos nuestros países, se ven enfrentados de alguna manera a la tecnología, al desarrollo, a la modernidad".

\section{BIBLIOGRAFÍA}

Arango Arango, Juan Pablo (marzo 20 de 2014). Superintendente Financiero encargado. Documento presentado en el V Congreso de Acceso a Servicios Financiero, Sistemas y Herramientas de pago de Asobancaria. Cartagena de Indias, Colombia.

Camargo, Andrea; Tatin-Jaleran, Clémence; Furt Goncalves, Leticia Gontijo (2014). Colombia hacia un sector de seguros inclusivo y universal. Recuperado el 28 de marzo de 2017. http://www.bancadelasoportunidades.gov.co/documentos/ Publicaciones_banca/diagnostico_microseguros.pdf

75 Villa Zapata, Walter (1998). Revista Ibero-latinoamericana de Seguros No. 12. Pontificia Universidad Javeriana. 
Circular Externa 029 de 2013. Superintendencia Financiera de Colombia.

Circular Externa 038 de 2011.

Circular Externa 049 de 2015. Superintendencia Financiera de Colombia.

Circular Externa 049, del 7 de diciembre de 2016.

Código de Comercio

Concepto 2010010535-002 del 30 de marzo de 2010. Superintendencia Financiera de Colombia.

Consejo de Estado, expediente 3110 de 1994, MP Libardo Rodriguez Rodriguez.

Contreras, Claudia (2016). Hay mercado potencial de US\$398 millones en primas de seguros en América Latina. Recuperado el 28 de marzo de 2017. http://www. estrategiaynegocios.net/finanzas/1002507-330/seguros-crecer\%C3\%A1n-6-enam $\%$ C3\%A9rica-latina-en-2016

Decreto 034 de 2015

Decreto 1367 de 1998

Decreto 1491 de 2015

Decreto 2555 de 2010

Decreto 2672 de 2012

Decreto 2673 de 2012

Decreto 673 de 2014

Departamento Nacional de Planeación. Bases del Plan Nacional de Desarrollo 20102014.

Diez años de la ley 389 de 1997 (2007). En: Ponencia del Capítulo de Medellín. Memorias del XXV Encuentro Nacional, Aspectos sustantivos y procesales del contrato de seguros. ACOLDESE, Medellín, Colombia.

Directiva Unión Europea 2016/97

Estatuto Orgánico del Sistema Financiero, modificado por la ley 1328 de 2009.

Fasecolda en acción (2016). Retos y oportunidades de los seguros de vida grupo e individual. Recuperado el 28 de marzo de 2017. http://www.fasecolda.com/index. php/sala-de-prensa/noticias/2016/febrero/accion-febrero-11-2016/ 
Fitzgerald, Michael (2015). Friendsurance: Challenging the Business Model of a Social Insurance Startup - A case study

Fundación MAPFRE. Recuperado el 28 de marzo de 2017. https://www.fundacionmapfre.org/documentacion/publico/i18n/catalogo_imagenes/grupo. cmd?path $=1060534$

Gaceta del Congreso 138. Proyecto de Ley 282 de 2008 de Cámara.

Guillermo Rueda, Manuel (1998). La Bancaseguros en Colombia. Revista Fasecolda.

- Bogotá : Unión de Aseguradoras Colombianos, 1979- = ISSN 0120-1972.

- 01/07/1998 Número 89 - 1998 , p. 28-35. Recuperado el 19 de noviembre de 2016. https://www.fundacionmapfre.org/documentacion/publico/es/catalogo_imagenes/grupo.cmd?path=1061031

Jaramillo Jaramillo, Carlos Ignacio (2017). Artículo en Homenaje al Profesor Andrés Ordoñez Ordoñez.

Ley 1328 de 2009

Ley 1450 de 2011

Ley 1700 de 2013

Ley 26 de 2006

Martinez Fernandez, Virginia (2017). Anteproyecto de Ley de Distribución de Seguros y Reaseguros Privados. Recuperado el 28 de marzo de 2017. https://www.hoganlovells.com/es/publications/anteproyecto-de-ley-de-distribucion-de-segurosy-reaseguros-privados

Martinez Franco, Juan Carlos. Gerente de Bancaseguros. Seguros de Vida Suramericana S.A., Seguros Generales Suramericana S.A.

Mora, Christian y Zarruk, Armando. Bancaseguros en la distribución de productos de vida. Revista Fasecolda. Recuperado el 28 de marzo de 2016: https://www. fundacionmapfre.org/documentacion/publico/i18n/catalogo_imagenes/grupo. cmd?path $=1060534$

Najera, A. (2014). 2013: Un año en transición. FASECOLDA, Edición 255, 2014.

Novaventa, Sura. Recuperado el 28 de marzo de 2016: http://www.novaventasura. com/default.aspx

Pinzón Fonseca, Daniel Andrés y Zarta Arizabaleta, José Fernando. La Oportunidad de Bancaseguros. Revista Fasecolda. 
Pinzón Fonseca, Daniel Andrés. La Experiencia de América Latina en Bancaseguros. Revista Fasecolda.

Redacción El Tiempo (1998). Bancaseguros, el nuevo mercado. Recuperado el 28 de marzo de 2017. http://www.eltiempo.com/archivo/documento/MAM-831210

Seguros Éxito. Recuperado el 28 de marzo de 2016: http://www.segurosexito.com/ default.aspx

Suraenlinea.com Recuperado el 28 de marzo de 2016: https://www.suraenlinea.com/ home

URF (2016). Documento técnico: Licitación de seguros asociados a créditos con garantía hipotecaria o leasing habitacional. Unidad de regulación Financiera. Recuperado el 28 de marzo de 2017: http://www.urf.gov.co/urf/ ShowProperty?nodeId=\%2FOCS\%2FP_MHCP_WCC-041662\%2F\%2FidcPr imaryFile\&revision=latestreleased

Villa Zapata, Walter (1998). Revista Ibero-latinoamericana de Seguros No. 12. Pontificia Universidad Javeriana. 